\title{
Differentiation of Amidase and $\beta$-Lactamase by Infrared Absorption
}

\author{
By M. J. CHAPMAN, R. J. HOLT, A. R. MATTOCKS AND G. T. STEWART \\ Queen Mary's Hospital for Children and the Medical Research Council Laboratories, \\ Carshalton, Surrey
}

(Received 27 January 1964)

\begin{abstract}
SUMMARY
The carbonyl- $\beta$-lactam absorption band of penicillins and cephalosporins at $1760 \mathrm{~cm} .^{-1}$ is detectable when the antibiotics are mixed with enzymes or bacterial protein. This band can therefore be used for differentiating the two inactivating enzymes $\beta$-lactamase and amidase. Examined thus, methicillin, cloxacillin, amino-cephalosporanic acid (7-ACA) and thienylacetamido7-ACA were stable to staphylococcal $\beta$-lactamase but less stable to coliform $\beta$-lactamase. Only quinacillin among a range of therapeutic derivatives tested resisted both types of $\beta$-lactamase. The other inactivating enzyme, amidase, can exist independently of $\beta$-lactamase in coliform organisms. When methicillin and cloxacillin were treated with amidase, they lost their stability to $\beta$-lactamase.
\end{abstract}

\section{INTRODUCTION}

In earlier papers (Holt \& Stewart, 1964a,b) we described microbiological and chemical methods for the identification of amidases of bacterial origin which act specifically on penicillin substrates by de-acylating them to 6-aminopenicillanic acid (6-APA). This enzyme can be identified with certainty, since the resultant 6-APA can be reconverted to benzylpenicillin by treatment with phenylacetylchloride. When the inactivating enzyme is a $\beta$-lactamase, however, identification is to some extent presumptive. We therefore sought a more direct method to differentiate $\beta$-lactamase from amidase, and to examine the effect of both enzymes upon a wider range of $\beta$-lactam antibiotics. It is known that the lactam ring of the various penicillins absorbs infrared emissions strongly and characteristically at a wavelength of $5 \cdot 6 \mu$ and wave frequency of $1760 \mathrm{~cm} .^{-1}$ (Thompson, Brattain, Randall \& Rasmussen, 1949). This absorption band probably depends upon the carbonyl linkage in the intact $\beta$-lactam ring. This band is in an unual position and, in some preliminary experiments, we found that it was clearly discernible by infrared spectrophotometry of 6-APA and benzylpenicillin, even in the presence of bacteria and enzyme protein. We therefore used this finding to study the effect of inactivating enzymes upon these and other $\beta$-lactam antibiotics.

\section{METHODS}

Infrared spectrophotometry. Pure 6-aminopenicillanic acid (6-APA) and 7-aminocephalosporanic acid (7-ACA) were made up in strong stock solutions in distilled water at $100,000 \mu \mathrm{g} . / \mathrm{ml}$., with the addition of sufficient potassium hydroxide to 
raise to $\mathrm{pH} 7 \cdot 0$. For experiments, these stock solutions were diluted to $100-500$ $\mu \mathrm{g} . / \mathrm{ml}$. in $\mathrm{M} / 15$ phosphate buffer at $(\mathrm{pH} \mathrm{6.0})$, at which both amidase and $\beta$-lactamase were active. Various derivatives of 6-APA and 7-ACA were similarly prepared without alkalinization. Solid potassium bromide (AR quality) was added to the solutions in the proportion of 200 times the weight of drug present. The solutions were then rapidly freeze-dried in vacuo, yielding an intimate fine-grained mixture of salt and drug. This was then moulded under high pressure in a hand-press with die to obtain a transparent disk, suitable for direct infrared spectrophotometry. With the use of slit micro-frame holders in a Perkin-Elmer Model 137 spectrophotometer, Perkin-Elmer Ltd, Beaconsfield, Bucks., England, as little as $100 \mu \mathrm{g}$. benzylpenicillin was adequate for a clear-cut absorption spectrum.

To examine the effect of enzymes, these solutions were mixed, as described in the experimental results below, with washed coliform organisms. In some experiments a cell-free semi-purified preparation of the enzymes (Holt \& Stewart, 1964a) was used, instead of washed bacteria, in the proportion of $50 \mu \mathrm{g}$. preparation to $500 \mu \mathrm{g}$. substrate. After incubation for $2-6 \mathrm{hr}$ at $40^{\circ}$, one drop of $0.1 \mathrm{~N}$-potassium hydroxide was added to form the potassium salt and thus ensure that no free carboxylic acid was present to obscure the $\beta$-lactam carbonyl peak. At stated intervals, the mixtures were centrifuged and the cell-free supernatant fluids, together with the appropriate blanks and standards, compressed into disks after the addition of potassium bromide.

Attempts were made to obtain better separation of the bands given by the $\mathbf{O H}$ and NH stretching bonds in the $3000-4000 \mathrm{~cm} .^{-1}$ frequency region. It was hoped by this means to show alteration in the stretching vibrations of the NH linkage of the side-chains of 6-APA derivatives; striking alterations of this nature might be anticipated as a result of amidase action on this link. Despite the use of various liquid vehicles as well as solid state disks, and examination with another spectrophotometer of much greater resolution at this wave-frequency, no alterations were clearly discerned. This failure was almost certainly due to the presence of traces of water vapour which could not be eliminated.

Tests for inactivation. The same solutions of penicillins and cephalosporins, with and without the addition of bacteria, were assayed by bore-hole bio-assay plate techniques for loss of antibacterial potency. Each organism examined for enzyme production was also re-tested by the membrane-plate technique against the same range of $\beta$-lactam substrates (Holt \& Stewart, 1963).

\section{RESULTS}

\section{Effect of coliform organisms upon penicillin substrates}

Benzylpenicillin and 6-aminopenicillanic acid. Fresh isolates of Escherichia coli were obtained from the routine laboratory. Eighteen-hr broth cultures of these organisms were centrifuged at $\mathbf{3 7 0 0} \mathrm{g}$ for $15 \mathrm{~min}$., and the deposit repeatedly washed with sterile distilled water to remove as much medium as possible. Samples $(0 \cdot 1 \mathrm{ml}$.) of a very dense suspension (now about $8 \times 10^{10}$ organisms $/ \mathrm{ml}$.) of these washed organisms were added to $1 \mathrm{ml}$. portions of the various penicillin solutions, at $500 \mu \mathrm{g}$./ $\mathrm{ml}$. in $\mathrm{M} / \mathbf{1 5}$ phosphate buffer at $\mathrm{pH} 6 \cdot 0$. After $2 \mathrm{hr}$ at $40^{\circ}$ with frequent agitation, a trace of potassium hydroxide was added, the bacteria removed by centrifugation and excess potassium bromide added to the supernatant fluid. The mixtures were 
freeze-dried, compressed into solid disks, and examined by infrared spectrophotometry. As controls, identical preparations were made without incubation, and also standards of penicillins at the same strength to which no bacteria had been added. A background control of potassium bromide + buffer only was also examined, to ensure that no unsuspected absorption bands were present.

Twenty successive isolates of coliform organisms were treated in this way; each organism was incubated with both benzylpenicillin and aminopenicillanic acid (6-APA). The organisms were also re-tested against these two compounds on membrane plates. This experiment (Table 1 ; Fig. 1) showed that 12 strains did not change the infrared absorption spectra or the activity of either substance; 5 strains abolished the activity of benzylpenicillin without affecting the carbonyl peak of the lactam ring, proving thereby that inactivation was not attributable to $\beta$-lactamase; 3 strains destroyed 6-APA and the lactam ring absorption spectrum, and were therefore producers of $\beta$-lactamase.

\begin{tabular}{|c|c|c|c|}
\hline \multirow{2}{*}{$\begin{array}{l}\text { No. of } \\
\text { strains tested }\end{array}$} & \multicolumn{2}{|c|}{$\begin{array}{l}\text { Membrane-plates } \\
\text { Destruction of }\end{array}$} & \multirow{2}{*}{ 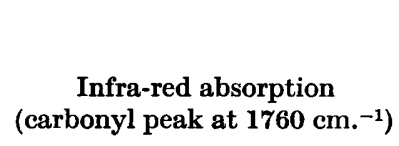 } \\
\hline & Benzylpenicillin & 6-APA* & \\
\hline $\begin{array}{r}12 \\
5 \\
3\end{array}$ & $\begin{array}{l}\text { Nil } \\
++ \\
.\end{array}$ & $\begin{array}{l}\mathrm{Nil} \\
\mathrm{Nil} \\
++\end{array}$ & $\begin{array}{l}\text { Present unchanged } \\
\text { Present unchanged } \\
\text { Absent }\end{array}$ \\
\hline \multicolumn{4}{|c|}{ * 6-Aminopenicillanic acid. } \\
\hline
\end{tabular}

Table 2. Reconstitution of benzylpenicillin after de-acylation by enzyme in Escherichia coli

$\begin{array}{cccc}\text { Tube* } & \begin{array}{c}\text { Content as benzyl } \\ \text { penicillin }(\mu \mathrm{g} . / \mathrm{ml} \text {.) }\end{array} & \begin{array}{c}\text { Percentage } \\ \text { recovery }\end{array} & \begin{array}{c}\text { Infra-red absorption } \\ \text { (carbonyl peak at } 1760 \mathrm{~cm} .^{-1} \text { ) }\end{array} \\ \text { A } & 410 & 90 & \text { Present } \\ \text { B } & \text { Nil } & \text { Nil } & \text { Present } \\ \text { C } & 275 & 60 & \text { See text }\end{array}$

* Tube A contained washed organisms of $E$. coli, no incubation, tube B contained washed organisms of $E$. coli, incubated $2 \mathrm{hr}$, tube C contained washed organisms of $E$. coli, incubated $2 \mathrm{hr}$, then treated with phenylacetylchloride.

$\dagger$ Original concentration after adding $1 / 10$ vol. organism $=455 \mu \mathrm{g} . / \mathrm{ml}$.

Reconstitution of benzylpenicillin after de-acylation. To tubes A, B, C containing $1 \mathrm{ml}$. lots of benzylpenicillin at $500 \mu \mathrm{g} . / \mathrm{ml}$. in $\mathrm{pH} 6.0$ buffer were added $0.1 \mathrm{ml}$. of washed coliform organisms shown by the above technique to form an amidase but no $\beta$-lactamase. Tube A was now centrifuged (4000 rev. $/ \mathrm{min}$. for $15 \mathrm{~min}$.). A trace of $\mathrm{N}-\mathrm{KOH}$ was added to the cell-free supernatant fluid, $0 \cdot 1 \mathrm{ml}$. fluid removed, diluted 1500, and heated at $75^{\circ}$ for $10 \mathrm{~min}$. Potassium bromide (0.125 g.) was immediately added to the remaining $1.0 \mathrm{ml}$. The two other tubes, $\mathrm{B}$ and $\mathrm{C}$, were incubated for $2 \mathrm{hr}$ at $40^{\circ}$; tube $\mathrm{B}$ was then treated in exactly the same way as tube $\mathrm{A}$. After tube $\mathrm{C}$ had been centrifuged, one drop of $5 \% \mathrm{NaHCO}_{3}$ was added to the supernatant fluid, followed by one drop phenylacetylchloride, and the tube shaken for 


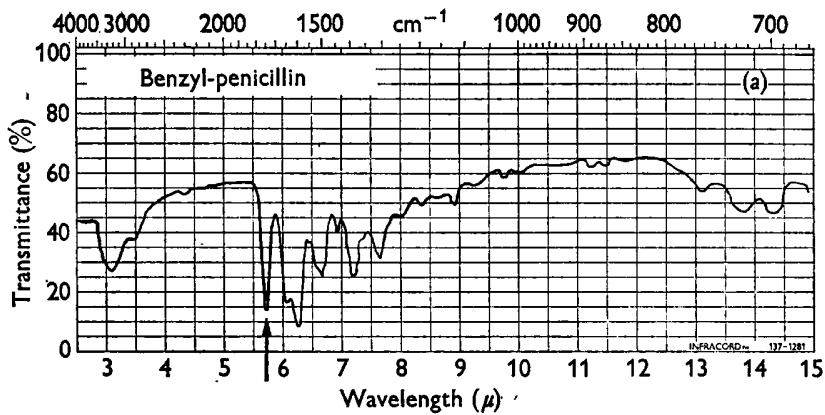

Fig. $1 a$

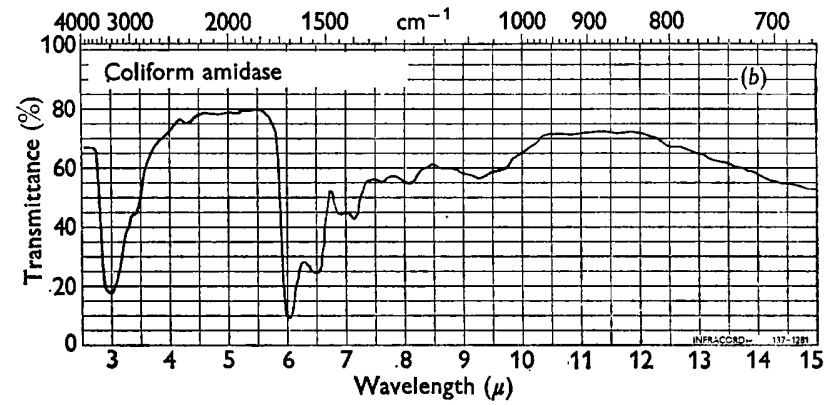

Fig. $1 b$

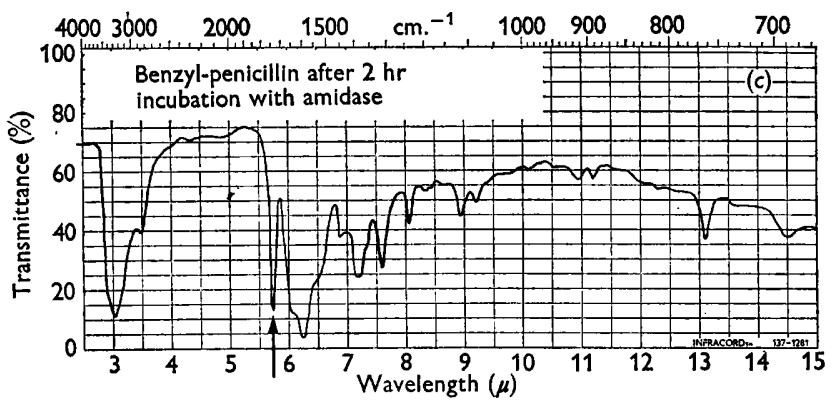

Fig. $1 c$

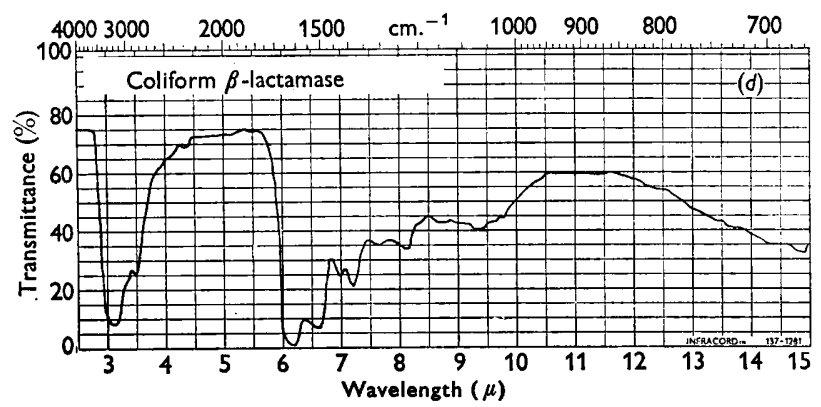

Fig. $1 d$

For legend and Fig. $1 e$ see opposite page. 


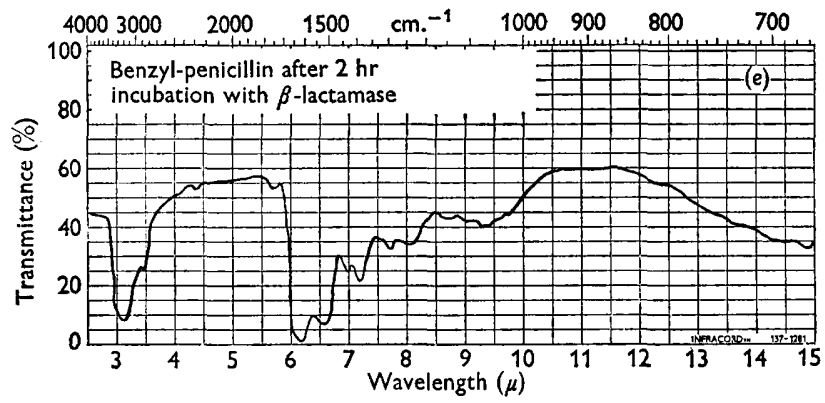

Fig. $1 e$

Fig. 1. Effect of enzymes from $\boldsymbol{E}$. coli on benzylpenicillin

$10 \mathrm{~min}$. Finally, one more drop of $5 \% \mathrm{NaHCO}_{3}$ was added and the fluid now treated as tube A. Plate bio-assay of the $1 / 500$ dilutions was carried out against a standard range of benzylpenicillin dilutions similarly heated. Infrared spectra of the bromide preparations (Table 2) showed preservation of the lactam ring in tube $\mathrm{B}$ with total loss of benzylpenicillin activity. No infrared trace was obtainable from tube $C$, the whole spectrum being obscured by the presence of phenylacetylchloride which had re-acetylated benzylpenicillin to $60 \%$ of the original concentration, as shown in the bio-assay. The above experiment was repeated with a different coliform strain

Table 3. Effect of inactivating enzymes upon $\beta$-lactam substrates

Infra-red absorption at $1760 \mathrm{~cm} .^{-1}$

Substrate

6-Aminopenicillanic acid

Benzylpenicillin

Methicillin

Cloxacillin

Ampicillin

Quinacillin

7-Aminocephalosporanic acid (ACA)

7-substituted 7-ACA deriv.

3,7 subst. 7-ACA deriv.

C.

$\begin{array}{ccc}\text { Coliform amidase } & \text { Coliform } \beta \text {-lactamase } & \text { Staph. } \beta \text {-lactamase } \\ \text { Present } & \text { Absent } & \text { Absent } \\ \text { Present } & \text { Absent } & \text { Absent } \\ \text { Present } & \text { Weakened } & \text { Present* } \\ \text { Present } & \text { Weakened } & \text { Present* } \\ \text { Present } & \text { Absent } & \text { Absent } \\ \text { Present } & \text { Present } & \text { Present } \\ \text { Present } & \text { Weakened } & \text { Present } \\ \text { Present } & \text { Weakened } & \text { Present } \\ \text { Present } & \text { Absent } & \text { Absent }\end{array}$

* The absorption band was abolished when methicillin and cloxacillin were previously treated with amidase.

possessing similar properties. Here again the carbonyl absorption band was still present after the microbiological activity of benzylpenicillin had been decreased to a very low value; this activity was largely restored by subsequent treatment with alkaline phenylacetylchloride. These experiments served to differentiate coliform organisms which produced $\beta$-lactamase from those which produced amidase. In the experiments which follow, washed organisms from two representative strains were used as enzyme preparations for testing against other substrates.

Semi-synthetic derivatives of 6-aminopenicillanic acid. The results are summarized in Table 3.

Neither enzyme preparation alone had any effect upon the carbonyl band of 
methicillin after $2 \mathrm{hr}$ or $4 \mathrm{hr}$. After $6 \mathrm{hr}, \beta$-lactamase caused less intense absorption at $1760 \mathrm{~cm} .^{-1}$, although the band was still clearly present. In a mixture of both enzyme extracts, the band was much weaker after $2 \mathrm{hr}$; after $6 \mathrm{hr}$, the band was almost absent.

The carbonyl band of cloxacillin was unaffected by the action of either enzyme alone after $2 \mathrm{hr}$, but the joint action showed considerable weakening of the band after incubation for $2 \mathrm{hr}$. In $6 \mathrm{hr}$ the band was weakened by $\beta$-lactamase acting alone.

Amidase alone had no effect upon the carbonyl band shown by ampicillin, even after incubation for $6 \mathrm{hr}$; within $2 \mathrm{hr} \beta$-lactamase had markedly weakened the band, and in $6 \mathrm{hr}$ there was no absorption at $1760 \mathrm{~cm} \cdot .^{-1}$.

The very strong carbonyl band of quinacillin was quite unaffected by either enzyme, even after incubation for $6 \mathrm{hr}$.

\section{Effect of cell-free amidase from Escherichia coli}

The derivatives of 6-aminopenicillanic acid listed above were tested also against semi-purified enzymes prepared from Escherichia coli (strains c. 11, c. 15, c. 33, c. 48, c. 236) as described elsewhere (Holt \& Stewart, 1964a). The results were identical to those obtained with washed concentrates of organisms from these strains, as described above, in respect of the effect of the enzyme upon the carbonyl band at $1760 \mathrm{~cm} .^{-1}$. There was, however, some masking of fine detail in other regions of the infrared spectra of the mixtures, due to the presence of a larger proportion of enzyme protein.

\section{Effect of coliform organisms upon 7-aminocephalosporanic acid and its derivatives}

The results are summarized in Table 3.

Apart from the parent compound 7-aminocephalosporanic acid itself, two derivatives were available for examination. One was a 3,7 substituted compound 3-pyridine 7 thienylacetamido-cephalosporanic acid: No. 87/4) and the other substituted in the 7 position only (thienylacetamido-cephalosporanic acid).

Amidase had no effect upon the strong carbonyl band of 7-aminocephalosporanic acid; $\beta$-lactamase showed a slight weakening of the band after $2 \mathrm{hr}$.

Amidase had no effect upon the carbonyl band of 3,7-pyridine-thienylacetamido-cephalosphoranic acid, but incubation for $2 \mathrm{hr}$ with $\beta$-lactamase showed complete removal of this absorption band from the infrared spectrum (Fig. 2).

The carbonyl band of 7-thienylacetamido-cephalosporanic acid was unaffected by amidase alone, but $\beta$-lactamase materially weakened the band after incubation for $2 \mathrm{hr}$.

\section{Effect of staphylococcal $\beta$-lactamase upon derivatives of 6-aminopenicillanic acid and 7-aminocephalosporanic acid}

Similar experiments were carried out with heavy suspensions of washed cocci of two strains of Staphylococcus aureus. One of these was a methicillin-resistant $\beta$-lactamase-producing strain (Stewart \& Holt, 1963), the other a methicillin-sensitive $\beta$-lactamase-producing strain. Each strain was incubated at $40^{\circ}$ for $4 \mathrm{hr}$ with solutions of 6-APA and 7-ACA and their various derivatives, at $500 \mu \mathrm{g} . / \mathrm{ml}$. concentration. Both strains of $S$. aureus were able to remove completely the $\beta$-lactam 


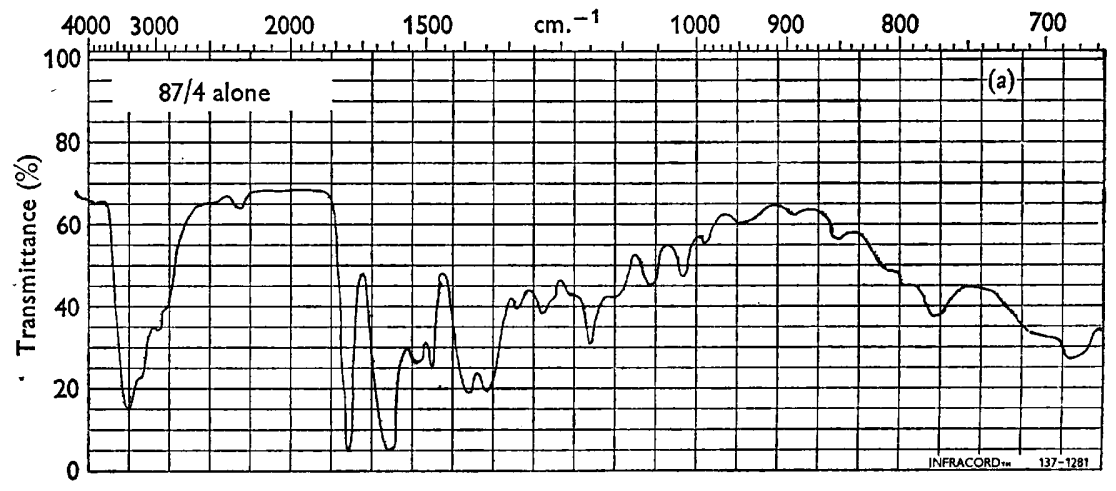

$a$

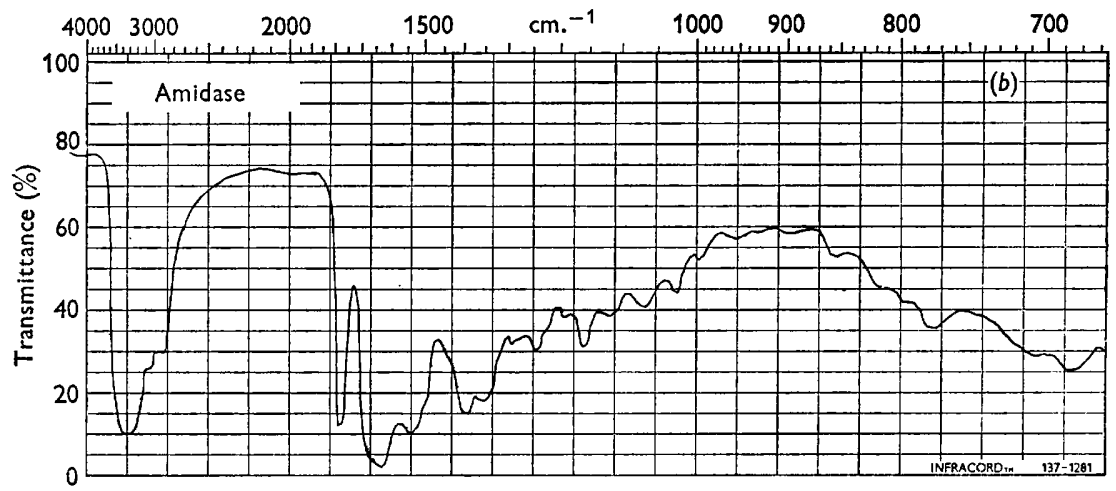

$b$

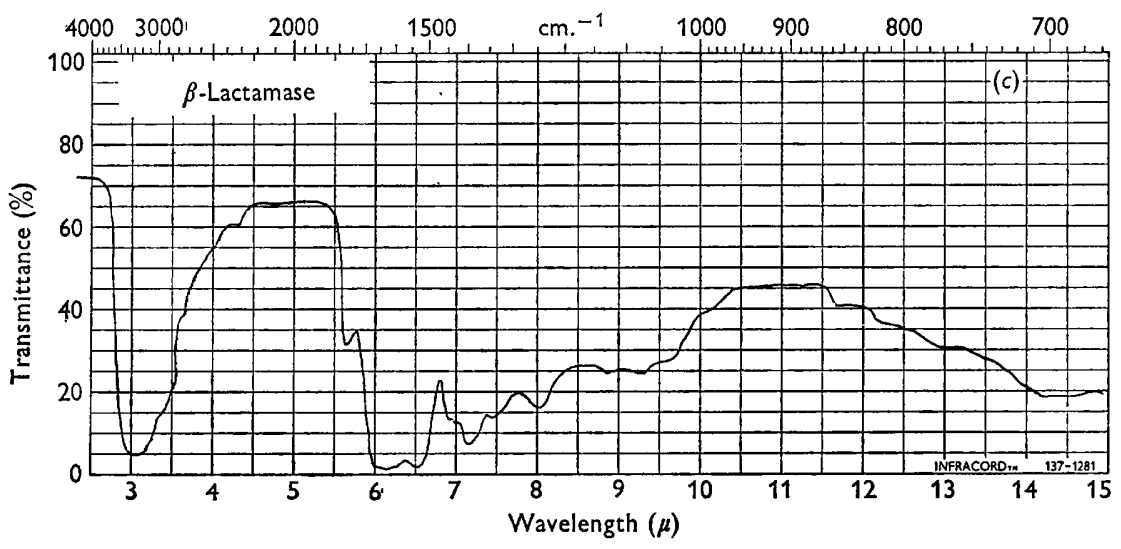

$c$

Fig. 2. Effect of enzymes from E. coli on 3,7 substituted derivative of 7-ACA (compound 87/4). 
carbonyl band from infrared spectra of 6-APA, benzylpenicillin and ampicillin; neither caused any alteration in this band in methicillin, cloxacillin or quinacillin within the stated time. Both strains caused complete loss of absorption in the carbonyl band from the 3,7 substituted 7-ACA derivative, but appeared to have no effect on the band with the parent compound or the 7-substituted derivative.

\section{DISCUSSION}

The experiments described here provide a direct means of differentiating the enzymic products of coliform organisms and staphylococci, with regard to their site of action on penicillins and cephalosporins. Coliform organisms may produce either of two inactivating enzymes: (i) a $\beta$-lactamase which abolishes all the antibacterial activity of 6-aminopenicillanic acid (6-APA), 7-aminocephalosporanic acid (7-ACA) and certain derivatives thereof, by hydrolysing the lactam ring; (ii) an amidase which does not alter the lactam-ring structure of 6-APA or 7-ACA but causes a lesser degree of inactivation by de-acylating the side-chains of some derivatives at the peptide linkage.

The $\beta$-lactamase-forming organisms can be identified directly by incubating whole-cell concentrates with substrate for a few hours; loss of the characteristic carbonyl absorption band at an infrared frequency of $1760 \mathrm{~cm} .^{-1}$ is conclusive evidence of this. Some organisms, however, inactivate derivatives of 6-APA and 7-ACA without altering this absorption band; the substrate residue can then be reactivated by phenylacetylation, proving that enzymes in this category have no action upon the lactam-ring and that de-acylation is clearly the consequence of a specific amidase present in coliform cells acting at the $\mathrm{CO}: \mathrm{NH}$ linkage of the sidechain.

The $\beta$-lactam antibiotics vary in their susceptibility to enzymes which attack the $\beta$-lactam ring. 6-aminopenicillanic acid, benzylpenicillin and ampicillin are completely hydrolysed, under given experimental conditions, by $\beta$-lactamases from coliform organisms as well as from staphylococci; whereas methicillin and cloxacillin, though resistant to the staphylococcal enzyme, are partially hydrolysed fairly rapidly by $\beta$-lactamase from coliform organisms. Of the penicillins tested, quinacillin is most resistant to each form of $\beta$-lactamase. 7 -aminocephalosporanic acid and its 7-substituted thienyl-derivative is stable to staphylococcal $\beta$-lactamase but partially hydrolysed by the coliform enzyme; but a more active 3,7-substituted derivative is hydrolysed by both forms of $\beta$-lactamase. The stability of methicillin and cloxacillin to $\beta$-lactamase is clearly of a high order but it is not complete. When exposed before incubation with an amidase, both compounds are rendered susceptible to the hydrolytic action of $\beta$-lactamase.

The results reported here relate to the interaction of bacterial enzymes and $\beta$-lactam antibiotics in vitro. There are undoubtedly differences, imperfectly understood at present, between any such findings and the behaviour of these compounds in vivo. It seems likely, however, that the readiness with which coliform organisms of human origin inactivate these compounds finds some counterpart in the interaction between the compounds and organisms in the body, especially when mixed infections are being treated. 
We are indebted to Beecham Research Laboratories Ltd., Glaxo Laboratories Ltd. and Boots Pure Drug Co. Ltd. for supplies of penicillins and cephalosporins; to Dr J. H. C. Nayler and Miss E. M. Tanner for valuable technical advice.

\section{REFERENCES}

Holt, R. J. \& Stewart, G. T. (1963). Techniques for the rapid and sensitive detection of penicillinase. J. clin. Path. 16, 263.

Holt, R. J. \& Stewart, G. T. (1964a). Penicillin amidase from coliforms: its extraction and some characteristics. Nature, Lond. 201, 824.

Holt, R. J. \& Stewart, G. 'T. (1964 $b$ ). Production of amidase and $\beta$-lactamase by bacteria. J. gen. Microbiol. 36, 203.

Thompson, J. W., Brattain, R. R., Randall, H. M. \& Rasmussen, R. S. (1949). In Chemistry of Penicillins, chap. 13. Princeton University Press. 